\title{
The Study of the Late Mediaeval Temple Architectures of Tripura (The North Eastern State of India)- A Style Evolved Due to the Multi-Cultural Assimilation During the Manikya Period
}

\author{
Mandira Dasgupta \\ Research Scholar, Department of Fine Arts, Tripura University
}

\begin{tabular}{|c|c|}
\hline ARTICLE INFO & ABSTRACT \\
\hline $\begin{array}{l}\text { Keywords: } \\
\text { Temple architectures } \\
\text { Cultural assimilation } \\
\text { Manikya period } \\
\text { Religions } \\
\text { Traditions }\end{array}$ & $\begin{array}{l}\text { The purpose of this study is to show the assimilated styles, motifs } \\
\text { and designs of the Late Mediaeval Temple Architectures of Tripura. } \\
\text { Like the other parts of India, Tripura has been an important centre } \\
\text { of interaction of several cultures and traditions. The state is a home } \\
\text { to numerous Tribes having different traditions and cultures. } \\
\text { Therefore there is a wide variety in the life style and cultures of this } \\
\text { state. Due to the friendly nature of the Manikya kings, the state was } \\
\text { globally well connected. In the Royal courtyard, many scholars, } \\
\text { artists, architects and other literates were invited for cultural } \\
\text { exchanges at that time. We can see the influences of those sharing } \\
\text { thoughts in the Architectures of this state. The temples constructed } \\
\text { during the late } 15^{\text {th }}-16^{\text {th }} \text { century exhibits motifs influenced from the } \\
\text { Indo-Islamic architectures, Bengal temples, Indo- Burmese style } \\
\text { and other indigenous elements of this region. These temples reflect } \\
\text { a synthesis of the arts, ideas, religious beliefs, values and the way of } \\
\text { life during the Manikya ages. }\end{array}$ \\
\hline
\end{tabular}

\section{Introduction}

Tripura is the state which has favored multiculturalism right from the beginning when it was ruled by the Manikya Kings ${ }^{1}$. During the $14^{\text {th }}$ and $15^{\text {th }}$ century, the Kingdom of Tripura consist the whole eastern region of Bengal having the Brahmaputra River in the north and west, the Bay of Bengal in the south and Burma to the east. At that time the Kingdom was ruled by the King Dhanya Manikya (1463-1515). This was the period when the capital was shifted to the Udaipur (before Udaipur was known as Rangamati). This city was the cultural hub with an assimilation of art and architectures around the $14^{\text {th }}$ century and presently is the third biggest city in the state Tripura. The power and fame of the rulers of that era have aroused to a great height that even the Mughals ruling in the North India have admired them. In Tripura, a good number of architectures have been built up in a different manner. These architectures were influenced from the local as well as from the neighboring countries like Bangladesh (Four-fifth of its land frontiers are enclosed by Sylhet in the north, Comilla in the west, Noakhali and Chittagong in the south-east) and the state of Assam and other north eastern regions.

There are various types of architectures which came up with several styles and designs, influences, characters or features, colours etc. Each of them carries the identity, cultural background of the society, historical significance, tradition, language etc of the state.

\footnotetext{
'Manikya' is the title of the kings of Tripura kingdom. The dynasty was founded when Ratna Fa (Ratna Manikya) assumed the title in 1280 A.D.
}

* Corresponding Author E-Mail Address: eyeris555@gmail.com 
According to the state chronicle 'Rajmala', the king's ancestry is being referred to the mythological Lunar Dynasty. In the $8^{\text {th }}$ century, the Kingdom shifted its capital eastwards along the Surma river in Sylhet near present Kailashar town of North Tripura.

The earliest historical records regarding the Twipra kingdom concern the 13th century, when it first came under pressure from the Islamic conquests in India. This is also the time of origin of the Manikya Dynasty, when Ratna Fa adopted the title Manikya. This sur-name was held by all the Kings of Tripura until the death of Bir Bikram Kishore Manikya in 1947. Ratna Fa shifted the capital to Rangamati on the banks of the river Gumti, now in South Tripura.

Tripura was first overrun by the Muslims under Tughril in 1279, but it managed to maintain its independence during the 14th through 19th centuries, until the British arrived. It was one of the states that pushed back successive waves of Jihadi invasions from Turks, Ethipian Muslims, Afghans, and Mughals. On many occasions the rulers have also pushed back Burmese and Arakanese invasions from the East. The Hill territories of Tripura, comprising present day Tripura state, Sylhet hills of Assam state, Cachar hills of Assam state, Mizoram state, and Chittagong Hill Tracts, remained free and independent before the British takeover. The Tripura Hill Kings were major sponsors of Hindu traditions and customs. In the modern age they are remembered as one of the longest and most stable dynasties from the Indian East.

Dhanya Manikya (1463 A.D-1515 A.D.) expanded Twipra's (Tripura's) territorial domain well into East Bengal. Rangamati was renamed Udaipur after Udai Manikya. The kingdom flourished in the 16th and 17th centuries, Kings such as Govinda Manikya(1660s) putting up a defense against the pressure of the Muslim kingdoms to the west, until the final conquest of the plains areas by a renegade Tripuri prince backed by Mughal governors of Eastern Bengal plains.

In British India, the kings retained an estate in British India, known as Tippera district or Chakla Roshnabad (now the greater Comilla region of Bangladesh), in addition to the independent area known as Hill Tippera, the present-day state of Tripura. Bir Chandra Manikya (1862-1896) modelled his administration on the pattern of British India, and enacted reforms including the formation of Agartala Municipal Corporation. Before the capital of Tripura was situated in Udaipur and ruled by several Kings until Krishna Kishore Manikya (1830 A.D -1849 A.D) who has shifted the capital to the Old Agartala (Khayerpur). Krishna Kishore Manikya has later shifted the capital to Agartala.

\subsection{Primitive Architectures of Tripura}

Tripura is home to Tripuri, Reang, Bhutia, Bhil, Chakma, Garo, Lepcha, Kuki, Lushai, Jamatia, Halam and Chaimal etc. with a number of sub-sects, each with distinctive ethnic origins and lifestyles. Most of these tribes reside in the five major hills like Boromura, Atharamura, longtharai, Shakhan and Jampui Hills.

The tribes especially the Riangs living in those hills constructs their Vernacular architectures made of natural wood, bamboo and thatch, straw etc. Most of the tribes practice jhum cultivation and were nomadic, therefore their houses were not made of masonry or stone. The houses were built in raised platform. Those were named as 'Stilt House' made of wood, bamboo and thatch as prime construction materials. These thatched houses have traditional steps made of a single wooden log and a square ground plan sometimes named as the 'Tong Ghar' (Figure 1).

The houses of the people living in the plain areas of Tripura are not similar to that of the tribal houses of the hills. There the people built the 'Plinth house' having mud walls (coated with cow dung) and bamboo as prime construction materials. But the use of mud and bricks was very rare in this region before. Migration of Bengali Community in the $18^{\text {th }}$ century onwards to Tripura brought architectural Style of Bangladesh in the region. 


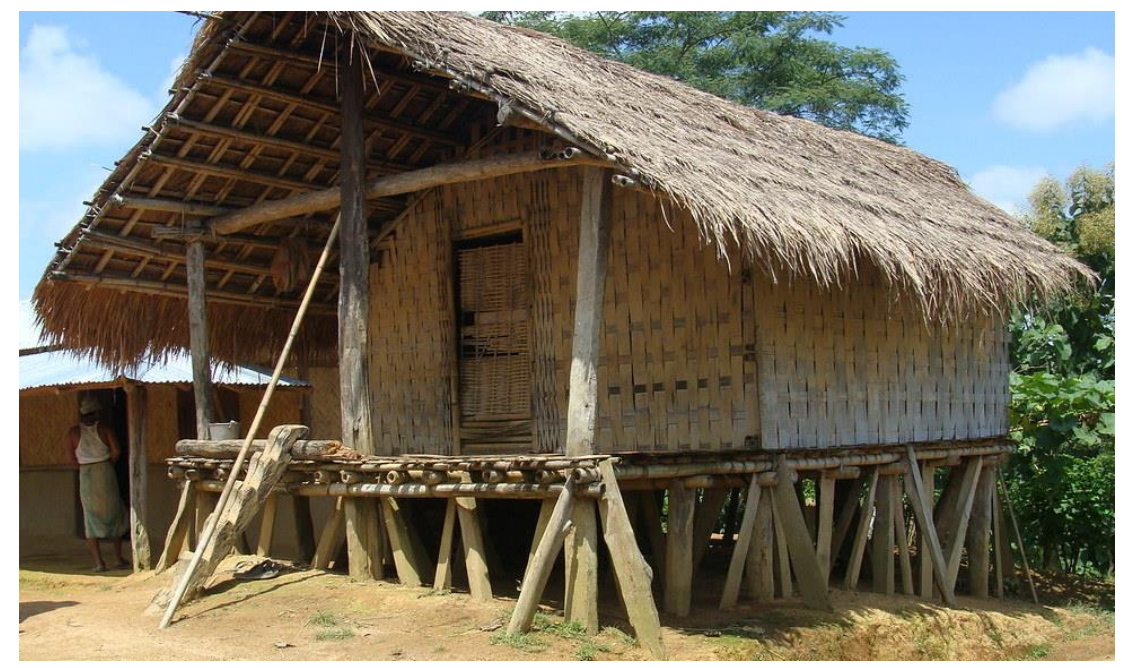

Figure 1: The Traditional Riang living-house. The construction of these types of house generally takes place in the dry season especially in winter since the construction materials like thatch/ timber/ bamboo are collected during winters only.

\subsection{Temples of Udaipur}

This present paper will illustrate the late mediaeval architectures of Udaipur. Udaipur is about $55 \mathrm{~km}$ far from Agartala, the present capital of Tripura. This city is dotted with ancient temples, mosques, palaces etc.

There are a wide numbers of temples located in Udaipur. Their names are as follows:

i. Tripura Sundari temple

ii. Temples located on the banks of Jagannath Dighi

a. Dol of Jagannath or Vishnu temple

b. HariMandir

c. Gundicha Bari

iii. Dharmashram Group of Temples

iv. Mahadev Bari Group of Temples

a. GopinathTemple

b. Tripuresh Siva Temple

c. Vishnu Temple

v. Duityar Bari Group of Temple

a. Jagannath Temple of Daityanarayan,

b. Temple of Dwitiya Devi

vi. Gunavati Group of Temples

a. Vishnu Temple of Gunavati

b. The other two temples are unknown

vii. Dol Manch Group of Temples (DolManch, Durga Temple), Old Palace Group of Temples

a. The Vishnu Temple of RamdevManikya

b. The Temple of Ratna Devi

c. The Vishnu Temple of RajdharManikya

viii. Temples on the Bank of DhanyaSagar

ix. Chandra Sagar Group of Temples

Only few among the above temples are in good condition today. Some of them were preserved by the ASI while others were ruined completely.

In this paper, the temple which exists till today will be described. 


\section{Methods}

The paper narrates about the Tripuri style of temples of the mediaeval period. The research is based on various archival sources, documentaries, literature works done in this area. The research has helped to highlight the basic concept of architectural form, motifs and structural designs made in those ancient days.

Those architectures comprises of a unique design with the amalgamation of Hindu, Buddhist and Islamic elements and motifs. Such a style is locally defined as 'the Tribeg style of architectures'. The word 'Tribeg' means the above three types of styles composed together. This paper also brings out the differences in the forms and styles of each of the architectures created in the similar time. It depicts the Hindu philosophy merged with Islamic pillars. The layout of the temples, its external and internal forms is tried to be described as far as possible. The paper also presents the various aspects of art, science and philosophy behind the construction of these ancient architectures. Various studies have been carried out from the field visits, self made drawings and information from the books, journals and websites.

\section{Structural Analysis of the temple architectures of Udaipur}

The use of stones for building purposes are not seen in Tripura. Rather the people use thin bricks for constructing their houses. The style of house building is also adapted in the temples. Thatched hut with a square ground plan are a familiar sight in rural Bengal from which later the Chala type of Bengal style has developed. According to Dr Goswami "...Curved cornice is one of the distinctive characteristics of the Muslim building in Bengal and this form may be traced to a construction in Bamboos or timber, a popular building medium in Bengal from the early days. The sharp superstructure over the roof is in juxtaposition with the domes, is also characteristically Bengal..."(Goswami, 2003)

In Tripura the Bengal style became a unique style which is termed as 'Stupa Sirsha Char Chala' or Tripura style of temple architecture. The temples of Tripura at the first glance resemble that of a hut with walls called bedas having equidistant Khaps under a Char Chala. The only difference is that the main four corner pillars termed as Palas, which generally are placed inside the bedas(walls) and is visible from outside. At joining of the four chalas stands the crowning which give these temples of Tripura an uncommon character. On this the Gambuj like superstructure stands the amalaka which resemble an inverted top on which stands the flagstand made of seven pitchers. The temples are with and without torana. Torana is do-chala construction. The ground plans of most of the temples are round inside and square from outside. A built in obelisk is placed in the centre of the sanctum to be used for placing the deities. Some of the nat-mandirs are being used even now and some are in ruins. Thus the Tripura style of temple architecture is unique. But the importance of Tripura temples does not lie in the hut shaped superstructure alone. It is the crowning which gives the monuments of Tripura a novel and unused form in Indian architecture according to Dr Goswami. Stupa with its component part is a very uncommon crowning in Indian monuments. No structural analogue of the type exists anywhere in India. Stupa Sirsha Char Chala temple is a universal combination of Brahmanical and Buddhist idioms of expression in religious architecture. The Tripura style of temple architecture is not only the combination of the Brahmanical and Buddhist style but it also accommodated the Indo-Islamic minarets to beautify the temples. The palas of the hut, being placed outside here, served the purpose of four minarets.

The only difference is that normally the minarets rise to the sky and have decorated top. But here the minarets stand below the hut with a kalasa on its head on which the joints of two chalas meet.

Thus the Tripura style of temple architecture is an unique style evolved out the combination of Hindu, Buddhist and Islamic style of architecture which reflects the status of religious 
toleration of the Hindu rulers of this small hilly kingdom though personally they follow the Brahmanism.

Such precious style of temple architecture started in Tripura during middle of the $15^{\text {th }}$ century and continued up to the middle of the $18^{\text {th }}$ century under the patronage of the Manikya kings of Tripura. We can understand more about this style if we examine the architectural style of the temple of Tripura Sundari.

\subsection{Study of the Mediaeval temples of Udaipur i. Tripura Sundari Temple}

Among all the ancient temples, the 518 years old Tripura Sundari Temple (fig-1) is the most famous temple which is standing still till today. Tripura Sundari Temple is one of the 51 Shakti Peethas and was constructed by the Maharaja Dhanya Manikya in 1501.There is a big lake beside the temple known as Kalyan Sagar. The temple was restored first by Ramdev Manikya in $1681 \mathrm{AD}$, later in the $20^{\text {th }}$ century by Radha Kishore Manikya. S Debbarman has related the temple with the Bengali hut type structures. (Debbarman, 1995)

Tripurasundari, as the name implies, is a presiding deity of the land and the people of Tripura. The temple is one of the 51 pitha pilgrims spots, of India associated with the mythical account of falling of the fragments from the body of Sati. The consort of Lord Shiva, Sati sacrificed her life for the sake of her husband's prestige.

According to an inspection note on the monument in the Tripura State by the Director General of Archaeology India on February19, 1952, there are two images of the same deity i.e. Tripurasundari inside the temple. One of the idols is called 'Chhotima' which appears to be the original image and measures about $2 \mathrm{ft}$ in height while that called Tripurasundari is about 5ft. The image of 'Chhotima' being much worn out it is it is difficult to date it accurately. Moreover the attributes in her hands are either too much blurred or lost. The lower right shows an inward bend of the palm as though it held something but the thing held is no longer there. Similarly, the lower left hand, which would have held a munda is also gone.

About the date of installation of the deities, the inspection note observes, the goddess Tripura sundari, being the tutelary deity of the Tripura Raj, seems to have been brought by these very rulers and may perhaps be dated to the $15^{\text {th }}$ century A.D. even on ground of style. The halo in the case of Chhotima is different from the halo that we see round the Triprasundari where it is multifoil.

This $75 \mathrm{ft}$ high temple is made up of bricks and the base is 3-4 $\mathrm{ft}$ above the ground. A particular space of 3-4 $\mathrm{ft}$ is kept for the circumambulation. The base of the temple connects to the ground with few steps.

\section{ii. Gunabati group of temples of Udaipur}

The Gunabati group of temples comprises of three brick temples adjacent to each other. These temples are situated towards the east of Udaipur town. Among the three temples, one on the northern side was built by Queen Gunabati, wife of the King Govinda Manikya(166076 A.D) in the year 1668 A.D. and was dedicated to God Vishnu. The other two have no inscriptions now, but the stylistic grounds appear to be of the same period. According to the author Das, the eaves of the charchala roof of the Gunabati temple (fig.2) are more drooping than those of the majority of the Tripura temples (Das, 1997). Five concentric moulded lines decorate the walls just below the cornice. Horizontal corbelled ribs on the walls are more projected and angular in appearance. The porch has no crowning. The most interesting member is an amalaka disc over the anda on which again is a solid spherical cube with angular ridges all around can be seen. Such characteristics are not seen in other temples. 


\section{iii.Vishnu temple}

This temple (fig-3) is situated to the south of the old palace of Udaipur. It is said to have been built by Ramdev Manikya (1677-85 A.D.) in the latter half of the $17^{\text {th }}$ century.

\section{iv. Mahadev temple}

This temple stands on the bank of the Bijoy Sagar. It is a very picturesque spot. The tank is excavated by Bijoy Manikya (1746-51 A.D.). In the stone inscription it was called as the temple of Sankara. The temple was built by Dhanya Manikya (1490-1520 A. D.). There is absence of porch in the temple.

\section{v. Bhubaneswari temple}

The temple of Bhubaneswari (fig-4) to the west of the old palace of Govinda Manikya stands amidst the leafy groves on the right bank of the Gomti river. It is situated to the eastern direction of Udaipur town. The temple was built by Govinda Manikya in the latter part of the $17^{\text {th }}$ century. Adjacent to this temple is the Govinda Manikya Palace which is restored now. This temple was said by the author Das to be built by Ramdeva- Manikya in 1677A.D. and dedicated to the God Vishnu. Ramdeva- Manikya has build this temple in memory of his fathe Govinda- Manikya. The temple is raised on a high plinth provided with stairways and an open ambulatory corridor. The porch is absent in this temple and the inner plan of the sanctum and the roof are identical with the Gopinath Temple.

\section{vi. The Hari temple}

This temple is a good example of the mediaeval temple architecture of Tripura because it carries all the features of that era. It consists of a dochala torana on its entrances which raises the devotee towards the higher platform of the temple. Like the other temples, this also consists of a spherical domed structure. The torana structure is unique with heavy walls and sitting stairs on the left and right sides with the assending and descending stairs. This temple isn't seen from distance now since the urban civilization has engulfed the space of its surroundings. But when we entered into these structures, we get a glimpse and ambience of the serenity of the bygone era.

\section{vii. The Jagannatha Dol}

This is different and the only existing stone temple of Tripura. Its features couldn't be studied clearly now since it is on the edge of deterioration. But references can be taken from the text written by Dr. Das.

"...The Jagannatha Dol or temple is the most important of all the monuments in Tripura as it is lone example of stone temple in the region...Though typical of the brick-temples, it is entitely built of ....ash coloured slate stone slabs, so far as the vertical portion is concerned. The inner vault and outer roof are, however, made of brick, but the base of the outer dome like the rest of the structures is of stone. Internally, it is square at the base; the square has been converted into a circle to form the inner vault by means of a series of eight arches. The arches occur one in the centre of each side and one at each corner above the heads of the main arches. Barrel-vaulted antarala contains one niche on either side. There are no images on the building though eleven niches are found on the exterior walls. The main features lies in the absence of ribs all around the building. The crowning is a massive hemispherical anda of a stupa, the other members being lost. Tapering pilasters with kalasa finial support four corners of the monument. The temple was built by Jagannathadeva, younger brother of Govindamanikya in 1661 and was originally dedicated to Vishnu..."(Das, 1997). 


\section{Results and Discussions}

The temples of Tripura built in the mediaeval period have less ornamental features. In these temples assimilation of the different chala style is seen which may be due to the contribution of Brahmanical and Buddhist idioms developed in these religious architectures. The chura or ratnas over chala and char chalas are found in the temples of West Bengal, Assam and Orissa. But in the temples of Tripura we can see the use of stupas over the hut shaped roofs. Tripura architectures not only adopted the Hindu and Buddhist idioms of architecture, but also introduced the Islamic designs to enrich it aesthetically. The cover buttresses of Tripura temples reveal the design of Indo-Islamic minars. All these temples were erected within a walled compound on a slightly raised stylobate, access to which was obtained by a torana. These were built of well burnt bricks and shale stones or in sometimes with fine-grained sandstone. In some of the temples steps were provided for reaching the top of the Jagati or the stylobate. It can be seen in the Hari Mandir of Udaipur which is also known as the Durga temple.

In most of the temples, mandapa with char-chala roof can be seen which also consist of the antarala giving access to the garbhagriha or the sanctum. The outer walls of the sanctum are of bricks, at four corners of which are four tapering buttresses, circular in shape and crowned by a kalasa or jar, from the top of which springs the carved cornice, imitating the eves of a thatched roof or char-chala hut.

Dr. Goswami has stated that "...the Buddhist missionaries of the south-east Asia who frequently visited the sacred Buddhist centres of India might have used the land route through Tripura in addition to the normal sea route. Tripura being situated at the cross road of such different cultural waves might have experienced the blending of Bengal and south-east Asian, particularly Burmese culture on its soil which is perfectly reflected in the style of the temple architecture of Tripura. Though it is a mixed culture yet with the unification of the local style it becomes a unique style of its own distinction. When the Muslim invaders entered Tripura through the western routes the physical features of Hill Tripura like the dense forest, undulated land, heavy rainfall and floods, unsuitable climatic condition that stood in the way of fast military movement helped the kings of Tripura in offering resistance. As a result the Muslims couldn't dominate the cultural life of Tripura, though the rulers of Tripura were defeated on many occasions by the Muslims, as they did in many other parts of India..."(Goswami, 2003).

The incomplete structure of the Mosque on the bank of Gomati at Udaipur, erected during the period described by the author Goswami in around 1621 A.D. is the historical evidence of that era. Thus the people have created their own indigenous style of architecture with the inspiration of Buddhism, Islamic styles etc.

\section{Conclusion}

The temples studied in this paper are defined as the mediaeval temple architectures of the state of Tripura on the basis of their architectural style. These temples are significant because of their crowning stupa like structures which is unique in its own way. According to Dr Das "... A few temples at Pagan in Burma- Abeyadana, Patothamya, Nagayon, Payathonju and Nat-hlaung Kyang, shows a complete stupa as the upper element, though tiered roof of the Pagan examples has been replaced by the charchala roof in our edifices. These Burmese monuments may hence be considered as the structural counterparts of the temples of Tripura..."(Das, 1997).

It is believed by many authors that when the Indo-Mongoloids of North-Eastern India came to power, the artists and architects started migrating to India from Burma through Chittagong and Assam. They started taking shelter in Tripura and they might have been patronized by the rulers of this state. Thus these architectural styles may have evolved. The history of these 
architectures is documented by several historians but the style and design has not been highlighted much. The temples of Tripura exhibit three features such as the Indian 'Chala' type of roof, Indo - Saracenic minarets and the Indo-Burmese type stupa crowning. The paper identifies these stylistic features and is an analysis of the structures of those temples. It also shows the synthesis of the arts, ideas, religious beliefs, values and the way of life during the Manikya ages. The paper explains why those monuments were created in that era.

It is regretting to see that most of those precious monuments are left in negligence, fighting with the climatic hazards, mishandling, dressed under the vigorous plastic paints and losing its aesthetic and historical values. Some of those monuments are being broken down, some getting lost in the forests, some being carried away by the river. If the proper research is still not done, then in future researchers couldn't even locate their exact location.

\section{Acknowledgment}

This paper is an output of the $\mathrm{PhD}$ research work carried by the author currently under the Department of Fine Arts, Tripura University, India.

\section{References}

Ahmed, K. (1994). The Art and Architecture of Assam. Assam: Spectrum Publications.

Acharjee, J. (2006). History- Culture \& Coinage of Samatata\&Harikela Volume-1. Tripura: Raj- KusumPrakashani.

Acharjee, J. (2012). BiluptaRajya 'Samatata' O 'Harikel' -erItihas O Samskriti. Tripura: RajKusum Prakashani.

Acharjee, J. (2012). Tripurar Itihas. Tripura:Raj- KusumPrakashani.

Baidya, A.K. (1987). Pratna- RatnaBhandarPilak. Agartala, Tripura: Naba Chanda Prakashani.

Bhattacharjee, P. B. (2011). A Living museum of Art, Architecture \& Culture. Agartala, Tripura: NabaChandanaPrakashani.

Bhattacharjee, P. B. (2013). The Religious life of Tripura special emphasis on Tribal Beliefs \& Practices, Agartala, Tripura: NabaChandanaPrakashani.

Bhattacharjya, C. V. (2012). ShilalipiSangraha. Agartala, Tripura: NabaChandana Publishers.

Bhattacharya, P. (2012). Bhaskarjya O Sthapatya-Shilpe Tripura (A Study on Sculpture \& Architecture of Tripura). Tripura: NabaChandaPrakashani.

Das, R. (1997). Art \& Architecture of Tripura. Agartala. Tripura: Tribal Research Institute Government of Tripura.

Debbarman, S. (1995). Tripura: A Look into Tripura. JnanBichitra.

Ghosh, N. (2014). Islamic Art of Mediaeval Bengal Architectural Embellishments. West Bengal: Amar Bharati.

Goswami, D.N. (1992). Tripur- Rajdhani Udaipur. Agartala, Tripura: The Directorate of Research Government of Tripura.

Goswami, D.N. (2003). Temples of Tripura. Tripura: Akkar Publications.

Goswami, D.N. (2006). Amar ManikyaMukut O Rabindranath. Agartala, Tripura: Akshar Publications. 
Goswami, D.N. (2016). Adhunik Tripura: PrasangaBirendra Kishore Manikya 1319-1333 Tring. Agartala, Tripura: Akshar Publications.

Goswami, D.N. (2016). RajarshiBhagya Chandra. Agartala, Tripura: Akshar Publications.

Chakraborty, P.P. (2006). Aytijher Udaipur A collection of essays. Udaipur, South Tripura: AbobahikaPrakashani.

Chakraborty, P.P. (2016). Ekanna Pith, Shakti SadhanaEbong Mata Tripura Sundari A details history of Tripura Sundari Mata \& Temple. Udaipur, South Tripura: AbobahikaPrakashani.

Chaudhuri, D. (1997). TripuraAnutathyapanji. Agartala, Tripura: GyanBichitra.

Chaudhuri, J.G. (2004). A Constitutional History of Tripura. Agartala, Tripura: ParulPrakashani.

Lahiri, K. (2013). Tripura Temples. Kolkata, West Bengal: Prativash.

Palit, B. (2016). Tripura PratnatatwikSampad. Agartala, Tripura: PounamiPrakashan.

Roy, P. (2003). ChaklaRoshanabad. Agartala, Tripura: Tripura Darpan.

Roy, P. (2016). Saktipeeth Udaipur. Agartala, Tripura: SaikatPrakashan.

Sandys, E.F. (2016). History of Tripura. Agartala, Tripura: Tribal Research \& Cultural Institute Govt. of Tripura.

Santra, T. (2014). A treatise on Temples \& Mosques of West Bengal. Kolkata, West Bengal: Pashchim Bangla Academy.

Sengupta, R. (2015). Puratani. Agartala, Tripura: BhashaPrakashan.

Sinha, R.J. (2016). Manipuri Sahitya-Sanskriti :TripurayCharcha O Prosar (A collection of essays on Manipuri literature \& culture in the perspective of Tripura). Agartala, Tripura: SaikatPrakashani.

Taylor, J. (2012). The Forgotten Palaces of Calcutta. Okhla Industrial Area, New Delhi: Niyogi Books.

Tomory, E. (2007). A History of Fine Arts in India and the West. Anna Salai, Chennai: Orient Longman Private Limited.

https://www.britannica.com/place/Tripura-state-India, 31/12/2018

https://trci.tripura.gov.in/different_tribes_of_tripura, 10/01/2019

http://www.tripura.org.in/heritages.htm\#Top, 11/01/2019 